\title{
A Computational Study of the Double Hydrogen Migration in the Molecular Ions of Endo Tricyclo[5.2.1.0 $\left.{ }^{2,6}\right]$ decene
}

\author{
Nico M. M. Nibbering \\ Physical Chemistry, Laser Center, Division Chemistry, Faculty of Exact Sciences, Vrije Universiteit, Amsterdam,
} The Netherlands

Wim J. van der Hart

Gorlaeus Laboratories, Leiden Institute of Chemistry, Leiden University, Leiden, The Netherlands

Previous field ionization kinetic experiments have supported strongly that the double hydrogen migration prior to the elimination of $\mathrm{C}_{5} \mathrm{H}_{8}$ from the molecular ions of the endo isomers of 8,9-disubstituted tricyclo[5.2.1.0 2,6 $]$ decenes, which is not observed for the exo isomers, proceeds in a concerted, i.e., dyotropic way. This paper describes the results of ab initio calculations at the ROHF/4-31G and DFT level of theory, performed on the double hydrogen migration for the ionized endo isomer of unsubstituted tricyclo[5.2.1.0 2,6 $]$ decene. An intrinsic reaction coordinate calculation at the DFT level has shown indeed a direct connection between the structures of the molecular ions of the endo isomer before and after the double hydrogen migration, thus corroborating the earlier suggested concerted, i.e., dyotropic pathway of this double hydrogen rearrangement. (J Am Soc Mass Spectrom 2002, 13, 1186-1189) (C) 2002 American Society for Mass Spectrometry

$\mathrm{O}$ ne and a half decades ago one of us has coauthored a publication on a dyotropic hydrogen rearrangement in the molecular ions of 8,9disubstituted tricyclo[5.2.1.0. $0^{2,6}$ ]decenes [1]. This rearrangement involves a double hydrogen migration from carbon atoms 8 and 9 to the double bond carbon atoms 4 and 3, respectively, in the ionized endo isomers 2 of the 8,9-disubstituted tricyclo[5.2.1.0 $\left.0^{2,6}\right]$ decenes to give ions 3 (see Figure 1).

The latter ions then eliminate $\mathrm{C}_{5} \mathrm{H}_{8}$ via a retro-DielsAlder reaction as shown in Figure 1. The double hydrogen migration and subsequent retro-Diels-Alder reaction are not observed for the ionized exo isomers 1 , where the distance between the hydrogen atoms of positions 8 and 9 and the double bond is too large for the hydrogen rearrangement required to effect the retro-Diels-Alder reaction (Figure 1). Support for the double hydrogen rearrangement as proceeding via a dyotropic reaction, i.e., the hydrogen atom migrations would be coupled to each other and occur in a concerted fashion (i.e., not necessarily synchronously or simultaneously), has been obtained from field ionization kinetic (FIK) experiments [1].

Such experiments enable to monitor in a continu-

Published online August 22, 2002

Address reprint requests to Dr. Wim J. van der Hart, Gorlaeus Laboratories, Leiden Institute of Chemistry, 2300 RA Leiden, The Netherlands. E-mail: w.hart@chem.leidenuniv.nl ously time-resolved way unimolecular decompositions of molecular ions as a function of their lifetime from $10^{-11}-10^{-9} \mathrm{~s}$ following ionization. For example, the exo isomer with $\mathrm{R}_{1}=\mathrm{R}_{2}=\mathrm{OCH}_{3}$ has been shown by FIK experiments to eliminate exclusively $\mathrm{C}_{5} \mathrm{H}_{6}$ over all molecular ion lifetimes studied, while the corresponding endo isomer eliminates both $\mathrm{C}_{5} \mathrm{H}_{6}$ and $\mathrm{C}_{5} \mathrm{H}_{8}$, but not $\mathrm{C}_{5} \mathrm{H}_{7} \cdot$ [1]. As expected, the $\mathrm{C}_{5} \mathrm{H}_{8}$ loss has been found to be a delayed process with respect to the $\mathrm{C}_{5} \mathrm{H}_{6}$ loss because of the required double hydrogen rearrangement, i.e., this channel starts to compete with the $\mathrm{C}_{5} \mathrm{H}_{6}$ loss at molecular ion lifetimes of $\approx 10^{-10} \mathrm{~s}$ and becomes dominant beyond molecular ion lifetimes of $\approx 10^{-9,25} \mathrm{~s}$. Important, however, is the absence of $\mathrm{C}_{5} \mathrm{H}_{7}$ loss, which is expected to occur for a stepwise, but not for a concerted, i.e., dyotropic double hydrogen rearrangement [1].

In the present work ab initio calculations have been performed on the double hydrogen migration reaction for $R_{1}=R_{2}=H$ to obtain additional theoretical support for the earlier suggested dyotropic hydrogen rearrangement as described above.

\section{Methods}

Preliminary conclusions on the shift of the two hydrogen atoms were obtained from a semi-empirical grid calculation. The results were used in subsequent restricted open shell Hartree-Fock (ROHF) 4-31G optimi- 


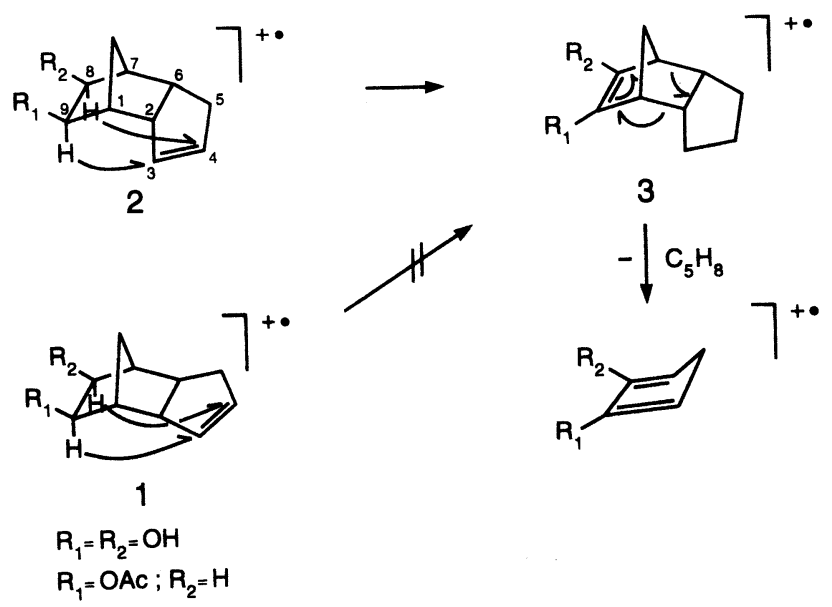

Figure 1. Experimental reaction scheme as described in [1].

zations of possible stable intermediates and transition states with GAMESS-UK [2]. These were used as starting points for more accurate density functional calculations using Gaussian 98 [3] with the B3LYP functional with Dunning's cc-pVDZ (correlation consistent polarized double zeta) basis set [4]. Transition states were tested by a visualization of the vibration corresponding with the single imaginary frequency with VIBRAM [5] or by intrinsic reaction coordinate (IRC) calculations.

\section{Results}

Figure 2 shows a semi-empirical (PM3) contour diagram where the coordinates $R_{1}$ and $R_{2}$ describe the motion of a hydrogen atom from $C_{9}$ to $C_{3}$ and from $C_{8}$ to $\mathrm{C}_{4}$, respectively (see Figure 1 ). The contour diagram suggests that, despite the large distance the hydrogen atoms have to move, the potential energy surface is

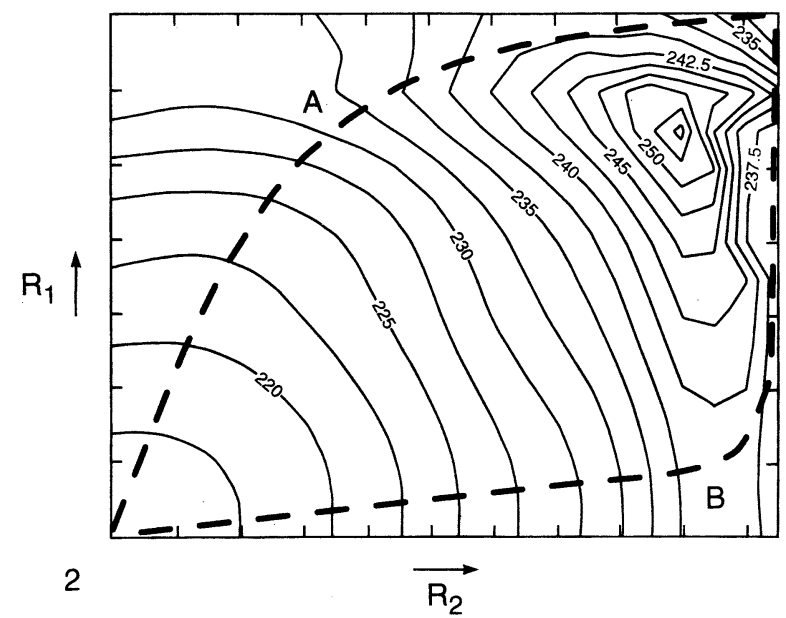

Figure 2. Semi-empirical contour diagram. The coordinates $R_{1}$ and $R_{2}$ describe the motion of a hydrogen atom from $C_{9}$ to $C_{3}$ and from $\mathrm{C}_{8}$ to $\mathrm{C}_{4}$, respectively. The distance between the contour lines is $2.5 \mathrm{kcal} \mathrm{mol}^{-1}$. The geometries of Structures $\mathbf{2}$ to $\mathbf{5}$ at the ROHF/4-31G level are shown in Figure 3.
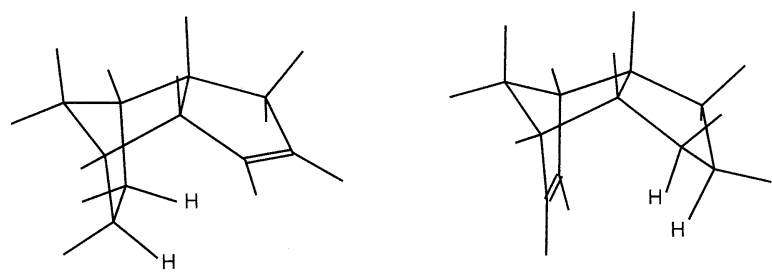

2

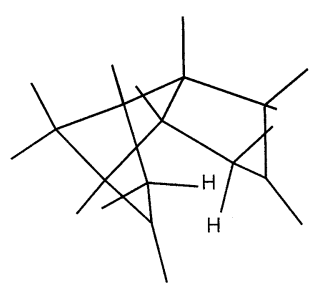

4

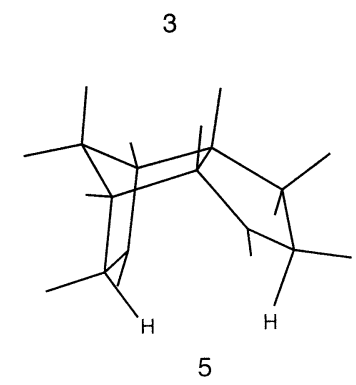

Figure 3. Ion geometries at the ROHF/4-31G level.

rather flat. It furthermore seems that there are two different possible pathways of almost equal energies for the reaction, one through the region near Structure 4 (path A in Figure 2) and one through the region near Structure 5 (path B), and that, when the internal energy is sufficient for the movement of one hydrogen atom, it will probably also be sufficient for the movement of the other hydrogen. This implies that, although Structures 4 and 5 may be stable, they are not necessarily intermediates during the reaction. The contour diagram thus indicates that the reaction is indeed concerted but not synchronous.

At the ROHF/4-31G level we could find acceptable geometries for the Structures $\mathbf{2}$ to $\mathbf{5}$ and for the transition states connecting them. These are shown in Figures 3 and 4 and the energies are given in Table 1 . Here, for example, $T_{3,5}$ stands for the transition state connecting Structures 3 and 5 .
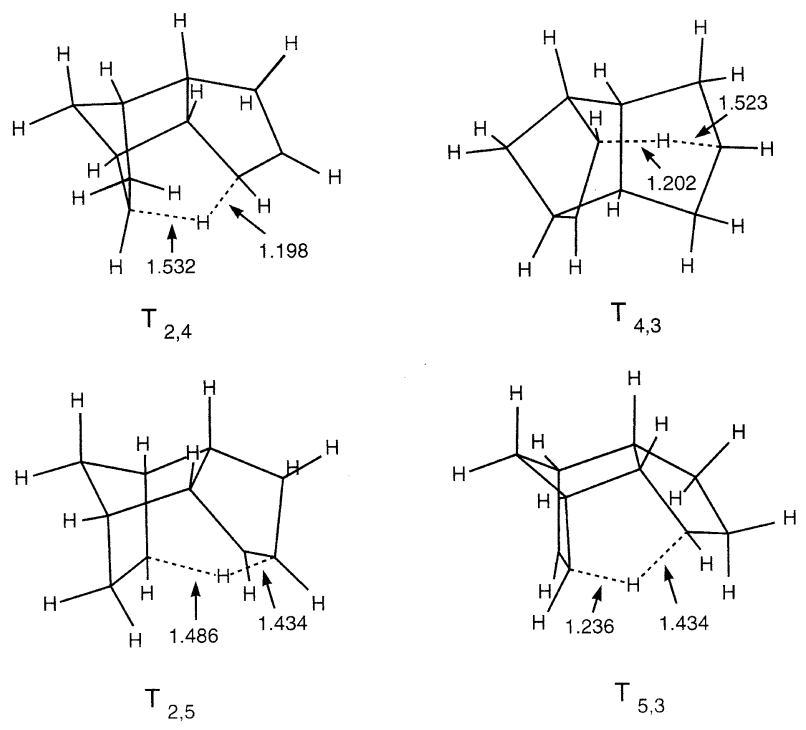

Figure 4. Transition state geometries at the ROHF/4-31G level. 
Table 1. Energies in Hartree at the ROHF/4-31G level and relative energies in $\mathrm{kcal} \mathrm{mol}^{-1}$ without correction for ZPE

\begin{tabular}{lcr}
\hline & Energy & $\Delta \mathrm{E}$ \\
\hline \hline 2 & -385.972143 & 0 \\
3 & -385.964948 & 5 \\
4 & -385.948550 & 15 \\
5 & -385.938814 & 21 \\
$\mathrm{~T}_{2,4}$ & -385.924917 & 30 \\
$\mathrm{~T}_{4,3}$ & 32 \\
$\mathrm{~T}_{2,5}$ & -385.921144 & 31 \\
$\mathrm{~T}_{5,3}$ & -385.923409 & 34 \\
\hline
\end{tabular}

In all cases except $T_{3,5}$, starting geometries were obtained from the semi-empirical calculations. For $\mathrm{T}_{3,5}$ a 4-31G calculation of the reaction path appeared to be needed. The results in Table 1 again show that all possibly involved transition states have essentially identical energies.

In some respects the results at the DFT/cc-pVDZ level (Table 2) were somewhat different from those at the ROHF/4-31G level.

Starting with the $\mathrm{ROHF} / 4-31 \mathrm{G}$ results, acceptable geometries could be found for the ion Structures 2, 3, and 4 and the transition states $T_{4,3}$ and $T_{5,3}$. Despite several attempts, including reaction path calculations at the DFT level, we were, however, unable to find a reasonable optimum geometry for the transition state $\mathrm{T}_{2,4}$. For this reason, an IRC calculation at the DFT level was done starting with $\mathrm{T}_{4,3}$. Because the potential energy surface is very flat, the distance the hydrogen atoms have to move is very large, and the calculations are very time-consuming, the standard step size in Gaussian 98 was increased by a factor of 5 after which a geometry optimization was done of the end points. This calculation showed a direct connection between Structures 2 and $\mathbf{3}$.

Larger differences between the DFT and ROHF/4$31 \mathrm{G}$ results were observed for Structure 5 and $\mathrm{T}_{2,5}$. A DFT optimization of the 4-31G geometry for Structure 5 went back to Structure 2 . This indicates that, at the DFT level, either Structure $\mathbf{5}$ is not stable or that the transition state to 2 has a rather low relative energy compared to 5. A DFT optimization of $\mathrm{T}_{2,5}$ from the 4-31G geometry started with one imaginary frequency of the ex-
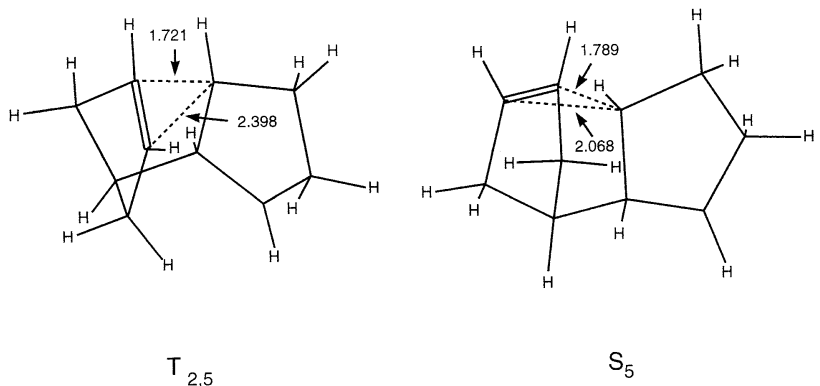

Figure 5. Geometries of $T_{2,5}$ and $S_{5}$ (see text) at the DFT level.

pected nature. After many cycles without large changes in the energy, an optimized geometry was obtained shown in Figure 5. This transition state geometry has an energy almost equal to those of $T_{4,3}$ and $T_{5,3}$. The structure, however, differs essentially from the 4-31G structure in Figure 4. In fact, it looks as the transition state for a reaction in which first a hydrogen moves as in the 4-31G geometry after which a bond breaking takes place forming a double bond in the 6-membered ring (see Figure 5). A subsequent calculation of the vibrational frequencies showed that the single negative force constant corresponds to this bond breaking. An IRC calculation starting with $\mathrm{T}_{2,5}$ at the DFT level showed a connection between $\mathbf{2}$ and the geometry presented as $S_{5}$ in Figure 5. It should be noted that this geometry differs from $\mathrm{T}_{2,5}$ : The distances of 1.721 and 2.398 in $\mathrm{T}_{2,5}$ become the distances 2.068 and 1.789 in $\mathrm{S}_{5}$, respectively. Despite this rather large difference in geometry, the energy of $S_{5}$ is only about $1 \mathrm{kcal} \mathrm{mol}^{-1}$ lower than that of $\mathrm{T}_{2,5}$ (Table 2). We therefore conclude that the geometry shown as $S_{5}$ is only some kind of local minimum and that Structure $\mathbf{5}$ is not stable at the DFT level. In addition, because the calculated energies of $T_{2,5}$ and $T_{5,3}$ are essentially identical (Table 2 ), we conclude that path $\mathrm{B}$ in Figure 2 also gives a direct connection between Structures 2 and $\mathbf{3}$ and that for both pathways $\mathrm{A}$ and $\mathrm{B}$ the energy of the transition state is about 21 $\mathrm{kcal} \mathrm{mol}^{-1}$.

\section{Conclusions}

The present calculations have shown that the potential energy surface associated with the double hydrogen

Table 2. Energies and ZPE in Hartree at the DFT level and relative energies in $\mathrm{kcal} \mathrm{mol}^{-1}$ corrected for the ZPE scaled by a factor of 0.985

\begin{tabular}{lccc}
\hline & Energy & ZPE & $\Delta \mathrm{E}$ \\
\hline \hline 2 & -389.179701 & 0.212498 & 0 \\
3 & -389.172670 & 0.213307 & 4.9 \\
4 & -389.160865 & 0.213733 & 12.6 \\
$5^{*}$ & -389.148186 & 0.212230 & 19.6 \\
$\mathrm{~T}_{2,4^{*}}$ & - & - & - \\
$\mathrm{T}_{4,3}$ & -389.145699 & 0.210783 & 20.3 \\
$\mathrm{~T}_{2,5}{ }^{*}$ & -389.144695 & 0.210925 & 21.0 \\
$\mathrm{~T}_{5,3}$ & -389.142579 & 0.210051 & 21.8 \\
\hline
\end{tabular}

* See text. 
migration from carbon atoms 8 and 9 to the double bond in the endo molecular ion of tricyclo[5.2.1.0 $\left.{ }^{2,6}\right]$ decene is very flat. The ion structures resulting from the single hydrogen transfer from either carbon atom 8 to carbon atom 4 of the double bond or from carbon atom 9 to carbon atom 3 of the double bond may be stable, but are not necessarily intermediates during the reaction. The direct connection found between the structures of the endo molecular ions before and after the double hydrogen migration supports strongly its concerted character as suggested earlier from field ionization kinetic experiments.

\section{References}

1. Kluft, E.; Nibbering, N. M. M.; Kühn, H.; Herzschuh, R. Dyotropic Hydrogen Rearrangement in the Molecular Ions of 8,9-Disubstituted Tricyclo[5.2.1.0 $0^{2,6}$ decenes as Supported by Field Ionization Kinetics. J. Am. Chem. Soc. 1986, 108, 7201.

2. Guest, M. F.; Fantucci, P.; Harrison, R. J.; Kendrick, J.; van Lenthe, J. H.; Schoeffel, K.; Scherwood, P. GAMESS-UK User's
Guide and Reference Manual, Revision C.0; Computing for Science (CFS) Ltd. Daresbury Laboratory: Daresbury, UK, 1992.

3. Frisch, M. J.; Trucks, G. W.; Schlegel, H. B.; Scuseria, G. E.; Robb, M. A.; Cheeseman, J. R.; Zakrzewski, V. G.; Montgomery, J. A., Jr.; Stratmann, R. E.; Burant, J. C.; Dapprich, S.; Millam, J. M.; Daniels, A. D.; Kudin, K. N.; Strain, M. C.; Farkas, O.; Tomasi, J.; Barone, V.; Cossi, M.; Cammi, R.; Mennucci, B.; Pomelli, C.; Adamo, C.; Clifford, S.; Ochterski, J.; Petersson, G. A.; Ayala, P. Y.; Cui, Q.; Morokuma, K.; Malick, D. K.; Rabuck, A. D.; Raghavachari, K.; Foresman, J. B.; Cioslowski, J.; Ortiz, J. V.; Stefanov, B. B.; Liu, G.; Liashenko, A.; Piskorz, P.; Komaromi, I.; Gomperts, R.; Martin, R. L.; Fox, D. J.; Keith, T.; Al-Laham, M. A.; Peng, C. Y.; Nanayakkara, A.; Challacombe, M.; Gill, P. M. W.; Johnson, B.; Chen, W.; Wong, M. W.; Andres, J. L.; Head-Gordon, M.; Replogle, E. S.; Pople, J. A. Gaussian 98, Revision A5. Gaussian, Inc: Pittsburgh, 1998.

4. Dunning, T. H., Jr. Gaussian Basis Sets for Use in Correlated Molecular Calculations. 1. The Atoms Boron through Neon and Hydrogen. J. Chem. Phys. 1989, 90, 1007.

5. Dillen, J. Program No. QCMP 12010. Quantum Chemistry Program Exchange, Indiana University: Bloomington, Indiana, 1992. 